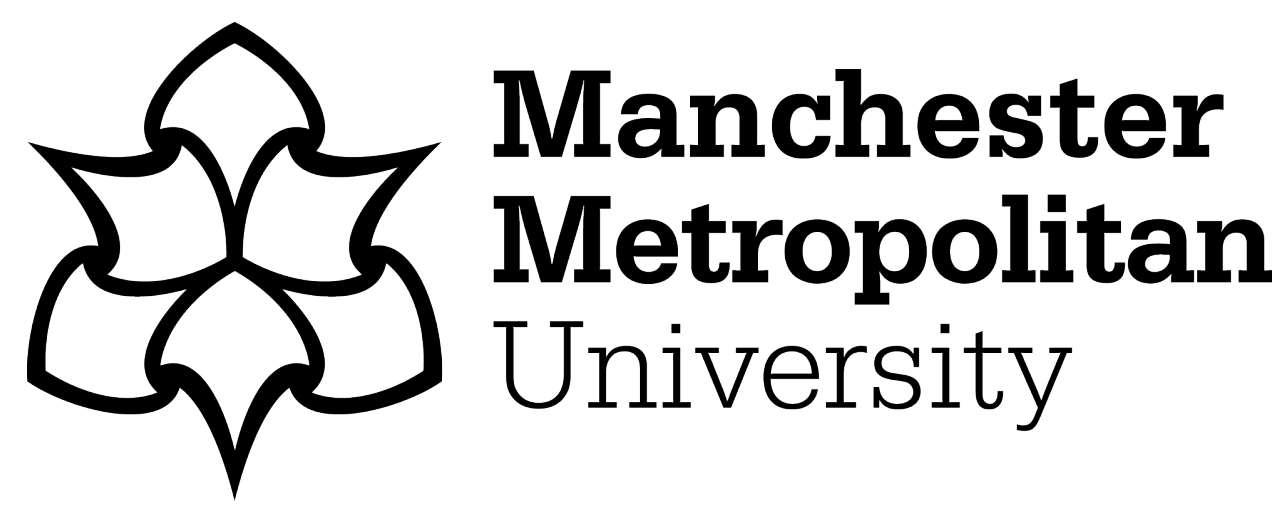

Brahic, Benedicte ORCID logoORCID: https://orcid.org/0000-0001-96788928 (2022) From expat mothers to migrant mothers: Narratives of transformations, lost privileges and the 'quieter' everyday in Brexit Britain. Journal of Ethnic and Migration Studies, 48 (9). pp. 2168-2186. ISSN 0047-9586

Downloaded from: https://e-space.mmu.ac.uk/626889/

Version: Accepted Version

Publisher: Taylor \& Francis (Routledge)

DOI: https://doi.org/10.1080/1369183X.2020.1851176

Please cite the published version 
From expat mothers to migrant mothers: Narratives of transformations, lost privileges and the 'quieter' everyday in Brexit Britain

\section{Bénédicte Brahic}

Department of Sociology

Manchester Metropolitan University

Email: b.brahic@mmu.ac.uk

Address: 4.01 Geoffrey Manton Building, Manchester Campus, Manchester Metropolitan University, Manchester M15 6BH, UK 


\title{
From expat mothers to migrant mothers: Narratives of transformations, lost privileges and the 'quieter' everyday in Brexit Britain
}

\begin{abstract}
Focusing on a key dimension of transnational family relations, this article explores the impact of uncertain migratory contexts and citizenship status on migrant mothering. Based on participant observations and semi-structured interviews with French migrant mothers living in Manchester, this paper explores how the UK's decision to leave the European Union ('Brexit') affects their identities as migrant mothers and their mothering practices. The paper explores the construction of the continuum of identities of female movers, wives/ female partners and migrant mothers in times of unprecedented social changes in modern Britain. It examines how Brexit affects European migrant mothers' lives with particular reference to cultural and linguistic maintenance and migrant community building. This article points to the affective, racialised and gendered dimensions of citizenship statuses and their susceptibility to changing political contexts. It underlines the need for conceptual developments to capture the affective, racialised and gendered dimensions of different migrant statuses to reveal some of their subtler dynamics. The findings highlight that, independent of actual policy and regulatory changes, shifting contextual norms of people's entitlement to family rights may induce changes in how migrants strategise and practise transnational family relationships.
\end{abstract}

Keywords: Affective citizenship; Brexit; France-UK migration; gendered and racialised citizenship; migrant mothering; normative context 


\section{Introduction}

Until the United Kingdom's (UK) referendum on its European Union (EU) membership (23 ${ }^{\text {rd }}$ June 2016), Western European nationals and their (often bi-national) families living in the UK had been relatively invisible in political and media discourses, in comparison to their Eastern European counterparts and (non-white) third-country nationals. They gained prominence almost overnight in the aftermath of the Brexit vote, with them feeling a deep sense of injustice that the lives and relationships they had built in the UK were under threat. This article explores how, although EU nationals' migratory rights had not yet changed and only limited changes were proposed in the future, the perceived injustice and threat felt by EU nationals in the UK stems from the changing 'affect' attached to their citizenship status and the anxieties inherent in 'suspense' citizenship (i.e. not knowing what one's status and rights will be).

Based on participant observations and semi-structured interviews with French migrant mothers living in Manchester, this article highlights the importance of the often elusive and taken for granted affective, racialised and gendered dimensions constitutive of people's family rights in a transnational context. To do so, it focuses specifically on the impact of uncertainties associated with impending changes in migration policies on transnational family-making and mothering practices, a key dimension of transnational family relations, which has important implications for citizenship, identity and belonging for women and their child(ren). By analysing the experiences of French mothers caught in the Brexit process, I explore two questions: (1) how the configuration of 'emotional' and 'affective' dimensions of (gendered) citizenship is affected by uncertain migratory contexts, and (2) what implications 'suspense citizenship' has for family life. The findings foreground normative context as a key constituent component of the process through which social justice pertaining to people's transnational family rights is constructed and evaluated. They show that independent of 
actual policy and regulatory changes, shifting contextual norms of people's entitlement to family rights may induce changes in how migrants strategise and practise transnational family relationships.

\section{Transformative journeys: Motherhood, migranthood, citizenship and belonging}

Although this article focuses on French mothers in Brexit Britain, it speaks to broader debates on the feminisation of international migration (Donato et al. 2006; Kofman 2004b). Gender ideology and inequalities shape women's experiences and patterns of migration, and motherhood plays an important role in defining many women's migratory experiences.

Miller $(2005,3)$ makes an important distinction between 'mothering', which encompasses women's personal experiences of caring and being responsible for devising mothering strategies for their dependent children, and 'motherhood', which is defined as 'the context in which mothering takes place and is experienced.' This distinction highlights the intimate and social dimensions of childrearing, which are intrinsically constitutive of mothers' experiences. Lawler (2000) observes that having a child often challenge women's sense of self, triggering a period of heightened self-reflexivity during which women try to reconcile their pre-motherhood self with the transformative demands of reproductive labour.

These transformations and how they are performed vary according to how class and ethnicity intersect to shape individual identities (Hill Collins 2016). Recognising diversity challenges normative (and othering) discourses, which, in Western societies, tend to equate 'ideal' mothers with white, middle-class, educated citizens in a heterosexual monogamous relationship (Phoenix, Woollett, and Lloyd 1991). Nonetheless, as Erel et al. (2018) note, racialised migrant mothers remain 'decentred' and are marginalised in both contemporary theoretical and political debates in the UK. In addition to challenging normativity, it is 
important to recognise the pervasiveness of 'local' discourses and ideologies about 'good' motherhood (Arendell 2000) against which mothers evaluate their own experiences.

Whilst family studies offer valuable insights into mothers' experiences in Western societies, migrant mothers remain relatively understudied, despite the growing population of migrant mothers in countries such as the UK. ${ }^{1}$ Migrant mothers were 'discovered' by migration studies following a call to 'bring gender in' (Kofman 2000), which resulted in 'bringing the family in' as well. Although family-related migration was initially overlooked in European research (Kofman 2004a), evidence suggests that family connections shape migration patterns (Ryan et al. 2009), which has led to an emerging body of research on EU migration and women.

Migrant mothers' experiences and practices are defined by the fact that their kin and cultural work operate across a range of geographical, social and ethnic localities (Reynolds and Erel, 2018) and citizenship statuses. Navigating complex contexts, migrant mothers draw on both local and transnational social networks to build their lives in their host country. Ryan (2007) demonstrates the importance of local and transnational networks for Irish female nurses to combine their work and family lives in the UK.

Social networks also play an important role in supporting (or inhibiting) migrant mothers' linguistic and cultural transmission, which often constitutes a key dimension of their mothering practices. Focusing on the personal lives (and networks) of French nationals living in London, Ryan and Mulholland (2014) highlight the role of full-time mothers in building family-based networks of sociability. Interestingly, these mothers' child-based sociability did not necessarily foster connections with local communities but instead drew them towards fellow French nationals. Many actively sought these contacts to maintain cultural and linguistic identities for themselves and their family (Ryan and Mulholland 2014). Establishing francophone friendships and being active in French-speaking networks were 
deemed critical by French-speaking parents in bi-national relationships who seek to maintain their children's bilingualism (Brahic 2013, Ryan, and Mulholland 2014). These typically women-led ethnic-based networks are important sites of experience sharing and emotional refuelling, where migrant mothers could take a break from being 'the other' (Brahic and Baldwin 2015). Feeling 'normal' and being recognised as a 'competent' mother form a key part of a quest for normalcy, which shapes migrants' mothering practices and strategies (Lopez Rodriguez 2010).

Crucially, through their reproductive labour-biological, cultural and social reproduction, migrant mothers raise future citizens (Reynolds and Erel 2018). However, enduring essentialist links between culture (imagined as rooted in fixed ethnicity), nationhood and citizenship mean the identities of transnational migrant mothers are characterised by geographical, social, cultural, linguistic multiplicities and 'in-betweenness'. As migrants, these women are kept at the margin of full citizenship; as mothers, their presumed multiple loyalties are conceived as a threat to ethnic continuity, unity and 'purity' (Erel 2009). Erel (2009) calls for migrant mothers to be reframed as citizens to challenge the gendered, ethnic, linguistic, cultural and social bases of citizenship, thereby widening current conceptualisations of citizenship to reflect the lives of migrant mothers who are de facto part of its very constitution.

Particular migrant positions inform and shape migrant mothers' experiences of national and supranational citizenship and their sense of belonging in the host country, including their identities and mothering practices. By studying the complex dynamics shaping women migrants' lives, Erel and Ryan (2018) developed an analytical framework that unravelled the interplay of macro-level socio-political factors, meso-level networks (families, migrant communities) and individual biographies with a spatio-temporal emphasis. Their framework highlights the connections between these levels and across different fields of 
migrants' lives, e.g. resources, capital accumulation through paid work, reproduction and citizenship. Crucially, 'a spatio-temporal analysis allows us to understand the synchronicity between individual biography, care and reproductive periods, migration trajectories and wider socio-spatial political contexts in historical time. These links can work to enable, shape and restrict opportunities and strategies for capital accumulation. The more migrants' life course is in tune with normative meso-level and macro-level social structures, the more opportunities may be available to build resources and capital' (Erel and Ryan 2018, 14). This article develops this analytical framework further through an exploration of the affective dimension constitutive of transnational migrant mothers' lives, as well as the crucial role of affect in (de)normalising the mothers' justice perceptions pertaining to their migratory status in their host country.

\section{(Not) feeling it? Intra-European migration and affective citizenship}

'Mothering is a flexible and transformative concept. As such, it should be conceptualised within the particularities of the social and cultural geographies that surround and the connected histories, representations and sociologies that shape its processes along the way' (Christou et al. 2015, 49). Characterised by their right to free movement, relative affluence, presumed whiteness and geo-cultural proximity, intra-European migrant mothers deserve to be studied in their own right. Crucially, representations of French nationality in the UK tend to imagine and construct French nationals as white. This may be linked to the fact that European identity (and by extension, French identity - see Beaman, 2019) is predicated on whiteness (Goldberg, 2006). The imagined whiteness of Western European migrants resident in the UK (combined with perceived economic, political and cultural proximity) place them 'high up' in the ethnic hierarchy that operates in the UK (Ford, 2011). Focusing on the experiences of French mothers living in the UK as Brexit unfolds, this article shows how 
migrant mothering practices are susceptible to changing contexts of motherhood (including citizenship and entitlement to [family] rights) and attendant emotions (e.g. change in the perception of self and perceptions of social [in]justice).

Intra-European migrants occupy a particular place in the British migratory landscape as they generally enjoy rights of free movement and abode, and have 'quasi-citizen' status in the UK. Favell and Recchi (2011) advocate the use of the term 'mover' to highlight the specificity of intra-European migration. The term is increasingly used in EU documents to signal broadening of free movement from 'workers' to 'persons'. Though their number remains low, ${ }^{2}$ movers carry high symbolic stakes for the European project in terms of 'Europeanisation from below' and 'lived' European citizenship (Favell and Recchi 2011). Whilst the term 'mover' is useful to distinguish intra-EU from non-EU migrants, it should not suggest that free movers form a homogeneous group. The EU enlargements in 2004 and 2007 marked the advent of a dual migration order that resulted in widespread disparities in the migratory experiences of Western and Eastern intra-European migrants (Favell and Nebe 2009).

Enjoying rights of free movement since 1992, Western Europeans migrating to the UK are typically white, middle-class, perceived as culturally close, and originating from countries of a similar economic standing as the UK. Their numbers have remained low. In 2016, EU-14 ${ }^{3}$ nationals represented $2 \%$ of the UK population (Office of National Statistics 2016). Crucially, the UK authorities never regarded their arrivals as a threat. Deemed 'unproblematic', they have been unmonitored and almost absent from political and media discourses. Favell and Nebe (2009) argue these factors have favoured these migrants' acclimatisation in the UK. In sharp contrast, concerns over an influx of 'poorer' economic migrants from Eastern Europe means the UK requires workers from $\mathrm{A} 8^{4}$ and $\mathrm{A} 2^{5}$ countries to register with the Accession State Worker Registration Scheme. State immigration policy, the 
2008 financial crisis and an increased media focus on Eastern European migration bred anxieties and negative attitudes towards Eastern European migrants in the UK. These factors have adversely shaped the migrants' experiences in the UK, particularly in terms of racialised discrimination (Fox, Moroşanu, and Szilassy 2012).

The terminologies used to reflect the disparate ways in which Western and Eastern European migrants are treated in the UK are illuminating. Though the term 'migrant' is increasingly contested, it is widely used in the media (McNeil 2013) to categorise internationally mobile individuals. Interestingly, for French mothers living in the UK, they seldom identify themselves as migrants and they loathed the term 'migrant' as an externally ascribed category. The term 'migrant' is emotionally laden and often carries negative associations with the general public; "constructions of migrants are frequently conflated with racialised, ethnic, national or religious Others" (Kunz, 2019: 2150). The racialisation of the term 'migrant' shapes ideas about bodies' perceived strangeness and their 'desirability' (Ahmed, 2007). For French nationals living in the UK who identify as white, being designated as a migrant reifies greater uncertainty vis-à-vis their migratory status. It also introduces a sense of differentiated whiteness and the concomitant threat that their particular white identity may become less desirable, more marginalised and, in turn, makes them feel less 'at home' in the UK than before Brexit. This ought to be acknowledged as constitutive of migrants' experience, the way in which migrants inhabit this identity, and their desire to belong to this category.

By contrast, the term 'mover' has little power of evocation outside debates concerned with intra-European mobility. Movers themselves do not use the term 'mover' to selfcategorise; rather, they tend to describe themselves as 'national $\mathrm{x}$ in country $\mathrm{y}$ ' or as an 'expat' with the assumed privilege this term implies. Foregrounding the affective dimension present in migration dynamics and underlining aspects of their post-colonial context, Sirkeci 
and Cohen $(2016,382)$ argue that the term 'expat' is 'almost exclusively used to refer to [the] movers from Western Europe, North America and a few advanced economies imposing a divide between perhaps the "undesirable" migrants and "likeable" movers.' Regulated by emotions, these perception and identification categories highlight the significance of affect in the construction of community membership (Fortier 2010).

What is in a name? Despite freedom of movement within the EU, movers and migrants continue to co-exist in the intra-European migration system. The suitability of the use of 'mover' - a term predominantly used by EU policy makers and researchers but rarely by movers themselves - to reflect the contrasting experiences of intra-European migrants is unclear. Whilst the term 'mover' highlights relaxed policies that regulate intra-European movement, it obscures borders and some of the ethnic and affective dynamics at play in intraEuropean migration. By contrast, the term 'migrant' reifies borders and otherness. In other words, the terms 'mover' and 'migrant' do not solely reflect geographical movements and the legal provisions regulating them; they convey complex social representations and aspirations and are loaded with symbolic meanings. These self-fulfilling terms both describe and shape categories of experience formed of the interaction between objective structures and subjective experiences that are constitutive of migrants and movers' lives, which relate to geographies, rights, policies, class, gender, and race. Amongst others, Cohen and Sirkeci (2011) argue for the demise of the term 'migrant' due to its pejorative connotations and restrictive meaning. However, the terms 'migrant' and 'mover' in intra-European movement appear more relevant than ever. They not only tell of distinct power relations and conflicts (Castles 2010) but also encompass the affective dimension attached to citizenship statuses. They allow for the exploration of the elusive ethnic and affective dynamics that are constitutive of these categories, which inform the experiences of individuals inhabiting them. 


\section{French presence in Brexit Britain}

Of the 154,800 French nationals residing in the UK, 95\% reside in England, 55\% are female, $79 \%$ are of working age, and, of those aged 16 to 64 years, $78 \%$ are working and $8 \%$ are economically inactive (Office of National Statistics 2016). Among those in employment, $65 \%$ worked in 'higher level professions' compared to $44 \%$ of the UK workforce as a whole (ibid.), suggesting that many French nationals live relatively 'comfortably' in the UK. As Western Europeans, French nationals living in the UK occupy a privileged position in the British migratory landscape as they enjoy free movement and benefit from a 'convenient' invisibility in the public sphere and a relatively welcoming attitude among the British public. The geographical proximity and shared history between the two countries mean the visual and audible markers of French migrants are often regarded positively in the UK. The status of the French language in the UK, which bears some familiarity and a certain prestige, is thought to support French-speaking parents' bilingual endeavours.

The 2016 EU referendum marked a crucial turning point in the social position of French transnational families in the UK. Although the Withdrawal Agreement passed into law in early 2020, there has not yet been any concrete regulatory change regarding the migration and family rights of EU citizens in the UK. Nevertheless, viewed as a normative shift in the context in which EU citizens' rights are constituted (Dodd, Lamont, and Savage 2017), Brexit has brought about a number of notable changes that are relevant to the study of transnational mothering. Brexit has rendered visible the previously taken-for-granted rights to Free Movement and transnational family life within the EU (Benson 2019). This has brought to the fore previously hidden forms of borders, which pass judgements on who are 'deserving' and 'undeserving' EU nationals in the UK and give rise to new 'hierarchies of belonging that reflect the moral values' of different diasporic communities (Benson 2019, 
502). Once made visible, EU citizens' rights of residing and leading a family in the UK become a clear object of regulation. This means uncertainties, anticipated legal and regulatory changes and the impending prospect of losing rights have turned the taken-forgranted sense of entitlement and ontological security among UK-resident French nationals on their head.

\section{Methods}

This paper is based on a combination of participant observations and semi-structured interviews, which form part of two research projects concerned with specific aspects of intraEuropean migration to the UK. The first project, entitled 'Reluctant Communities: The Social Implications of Bilingual Parenting,' explores how bilingual parenting shapes Polish, Finnish and French migrants' (networks of) sociability and sense of identity as well as patterns of community formation. ${ }^{6}$ The second project, 'Leaving or Living Brexit Britain: EU Migrants in the New age of Migration,' explores the impact of Brexit on French migrants and their families in the UK. Both projects address similar issues albeit in different migratory contexts (pre-Brexit and post-Brexit referendum). I brought these two projects together to form a 'comparative' dataset to explore how contextual changes created by the Brexit process affects French migrant mothers' experience of mothering and motherhood in the UK.

Located in the North West England, Manchester, the study area, is one of the largest conurbations in the UK. More affordable than London, yet economically dynamic and cosmopolitan, Manchester is an attractive hub for a growing number of European migrants (Manchester City Council 2015). Whilst seven out of ten Greater Manchester boroughs had 'Leave' majorities in the Brexit referendum, three chose to remain in the EU, including the borough of Manchester itself, where 60.2\% voted to remain (Electoral Commission 2016). 


\section{Participant observations}

Bringing a longitudinal dimension to the study, my participant observations started in January 2016, approximatively six months before the Brexit referendum $\left(23^{\text {rd }}\right.$ June 2016) and were completed in January 2018. They took place during bi-monthly free playgroup sessions (aimed at Manchester's French-speaking families), during which children (aged 6 months to ten years old) could play whilst their mothers and carers (typically French women aged between 20 and 45) could talk.

As a French national living in Manchester with a bilingual family, I am a member of the community I study. I have an opinion on and personal experience of Brexit. Whilst participant observations enabled me to collect rich, 'naturally-occurring' data and get a sense of the (evolving) mood and narratives among my participants, they are by no means perfect. As a researcher, I was constrained by circumstances; I had limited control over topics of conversations and limited opportunities for targeted prompting. Children also frequently interrupted the mothers and carers. The number of participants was limited and their participation was susceptible to potential self-selection bias (i.e. their desire for their child[ren] to grow bilingually partly motivated their participation in the group). Whilst participants seemed comfortable exchanging opinions, the presence of fellow participants may have hindered or amplified some of their views.

\section{Semi-structured interviews}

Fifteen semi-structured interviews were carried out over a similar period of time with six French mothers from the playgroup in which the participant observations took place, as well as nine French mothers who were recruited via purposeful and snowballing sampling. All fifteen interviewees lived in relatively affluent suburbs of Manchester. Aged 25 to 56 years old, all the respondents were white and middle-class and held a university degree. Four were 
stay-at-home mothers, three were self-employed (as health, education and art practitioners), eight were employed (two worked part-time, six in the education sector and two as office workers). Two respondents were single (separated) and thirteen in a heterosexual relationship (one with a French national, one with a third-country national, one with a European national, one with a British dual national and nine with a British national). All declared bringing up their children in at least two languages. The interviews complemented the participant observations and proved useful to explore the respondents' views and attitudes.

Field notes and interviews were analysed manually to identify recurring themes (such as the practices around 'parenting with difference', and their impact on the experiences of the migrant mothers). A manual approach was preferred to retain the flow of participants' narratives, familiarity with the data, and to capture the emotions at play during data collection. Pseudonyms are used to protect ensure anonymity and confidentiality.

\section{Findings}

The empirical case explores the gendered, racialised and affective dimension - and the fragility — of migrants' citizenship, justice perceptions, and their impact on family practices. Specifically, it focuses on the impact of uncertain migratory contexts (occasioned by macrosocial changes such as Brexit) on migrant motherhood and mothering practices.

\section{French expat mothers and mother expats in pre-Brexit Manchester}

This section presents a 'pre-Brexit referendum' baseline. It captures some of the key characteristics of the mothering experiences of middle-class French women living in Manchester, focusing on the negotiation of their identities as foreign mothers and the implications of bilingual mothering for their lives in Manchester. 
Bilingualism and a shared ambition for their children to be bilingual informed and shaped - and perhaps, for some, defined - their experiences as French mothers in the UK, as it implied making choices (e.g. in activities, networks of sociability, and career) to fulfil this goal. Marie explains how raising her daughter bilingually shapes her life as a migrant mother:

I over-invested in bilingualism and my role as a mother... It became a profound engagement. To me, it was more than important, it was something visceral...That's why I did not have a career here; this project not only required money but also time... I started everything again to maximise the role of the French-speaking community in our life. It is a choice. ${ }^{7}$

Many mothers in my sample elected to adopt a similar language strategy for their bilingual families, whereby each parent speaks their mother tongue to their child(ren). Interestingly, this strategy translated into a diverse range of practices. The topic discussed, the moment of the day, the interlocutor(s) present, and the context of interaction all had an influence on the language spoken by mothers with their child(ren), and led the families to adopt what they regarded as the best model to support bilingualism.

Raising their child(ren) in a bilingual environment did not appeal to all of the mothers. The migratory status of each woman at the time of their childbirth had a significant impact. For women who migrated to Manchester with their child(ren), they had to incorporate their children into their life in Manchester from the very start. Whilst some relished moving to Manchester, the majority had not actively chosen to do so. Their partner (typically a nonUK national) had secured a position in Manchester, and these women became 'accidental', and occasionally reluctant, movers to keep the family together. They were often not in paid employment or went on a career break. Upon arrival, some of the women had a limited 
command of English. This, compounded with the demands of resettling a young family and the absence of relatives and friends to support childcare, made it difficult for them to find employment (see also Ryan 2007). As a result, many found that French-speaking playgroups and networks provided them with an opportunity to socialise while supporting their children's bilingual education (see also Ryan and Mulholland 2014). Interestingly, several of the women invested in organising the playgroups, which rendered them more visible in their local ethnic community and extended their network of sociability. One of them explained how she built her network from scratch through participating in French-speaking groups, eventually becoming the president of a local organisation of 'French expats' (her choice of term), which, in turn, helped her set up her own business: 'now, I no longer have to worry about 'making my mark" here.'

The French women who became mothers after their arrival in Manchester gave a contrasting account of the impact of bilingual upbringing of their children on their lives. Unlike accidental movers, these women voluntarily chose to migrate. They deliberately moved and settled in the UK out of work, study, lifestyle or personal reasons. In this sense, they were 'aspirational movers'. Some expressed cosmopolitan ambitions and described travelling and living abroad as making them 'citizens of the world': 'I came here in the Erasmus spirit... It was to go to another country and discover its culture. It was as if we were Europe; I felt European' (Caroline). Many took pride in building relationships with 'locals' (these women were often in a relationship with a British national) as well as with international crowds. Some described avoiding fellow French speakers to maximise opportunities to speak English and interact with anglophone residents; others criticised fellow French movers for being unwilling to adapt to life in the UK. However, a closer examination of the friendship networks of this group of mothers often revealed dense co-ethnic ties. Although many fell short of their ideal of leading a cosmopolitan life, their migratory 
experiences led them to consider themselves as somewhat hybrid — that is, not the aggregation of two existing entities, but rather the sheer creolisation (Cohen 2007) of their sense of self. These women valued their experiences as movers and the state of in betweenness that came with life across borders.

Choosing bilingual parenting led them to re-engage with their French origin in their everyday lives, in their homes, with their partners and friends, and when socialising with their child(ren). 'French reappeared in our lives the day our daughter was born' (Catherine). These changes - compounded by the personal 'revolution' of becoming a mother — sat at odds with the lives they had imagined for themselves as movers. The practical and social implications of the bilingual project for their child(ren) contradicted their own personal cosmopolitan aspirations. This said, many admitted enjoying participating in French-speaking playgroups and networks, and sharing experiences and 'war stories' on (bilingual) parenting in the UK with fellow French mothers.

Whilst my respondents' migratory trajectories informed their experiences of mothering in the UK, opting for a bilingual education gave them all a sense of pride. FrenchEnglish bilingual education was deemed a positive thing. The respondents felt confident in their choice and rationalised it on a variety of grounds, such as enabling communication across borders, preparing for the global world of work, and allowing their child(ren) to know their mother more 'fully'. Audrey wanted 'to share songs, cultural references, jokes with (her) daughters; I want them to know me fully, and that they know my hidden self.'

Several participants recalled episodes during which their friends, family members and strangers questioned them - and occasionally challenged them — on their choice and practices of bilingualism. Nevertheless, none of them felt worried about possible racism or racial abuse against their children and themselves. Their accounts suggest a positive and relaxed practice of bilingual parenting where speaking a minority language in private and public contexts with 
different types of interlocutors is experienced as non-threatening. Many recognised the privileged character of their lives as middle-class French mothers in affluent suburbs of Manchester where French nationals, the French language and culture, are often deemed 'desirable'. They also recognised that these privileges did not extend to all migrants (a category with which many participants did not identify). ${ }^{8}$ However, despite being aware of their privileged position, the participants often generalised from their own experiences to describe Manchester (and the UK) as a welcoming, open and cosmopolitan place for migrants.

\section{The shock of Brexit: becoming a 'migrant mother'}

To capture how the Brexit process informed my participants' experiences in the UK, it is important to consider the participants' opinions on the Brexit referendum. Except for one respondent who was sympathetic to Brexit, all other participants objected to the UK leaving

the EU. As the referendum approached, Brexit emerged as a recurrent topic of conversation among the respondents who previously appeared uninterested or quietly confident. An increasing number of them had 'a bad premonition' (Caroline) brought about by a series of 'warning signs' (Mireille). Though several respondents admitted they had 'a bad feeling' about the referendum, they did not want to 'believe in their rational mind' that Brexit could become a reality.

All felt shocked by the referendum result. In her interview, Sandrine recalled at length the night of the referendum result and the anguish she experienced.

It was a shock. I stayed up all night. This is forever imprinted in my memory... that night when I saw the shock coming. I will never forget this date because it was so important to me. I love England, I have always loved 
their language and culture. It was part of me that was... torn apart. I was torn apart. I was forced to be French... and could not be both (i.e. French and English), which had suited me very well.

Like Sandrine, several respondents, especially the 'aspirational' movers as opposed to more reluctant movers, felt the Brexit referendum result forced them to choose an identity and denied them the possibility of multi-layered non-essentialist hybrid identities. As the wife of a dual national and a mother who brought up her children across several cultures, Mireille found this denial particularly hurtful:

We have a bit of a hybrid status. I don't want my children to live on a nationalist island. We are a multilingual family; my children were born in three different countries. We (as a family) are truly European.

Several other respondents echoed this account and felt rejected, which led them to reconsider their position in and relation with their (imagined) host country. By comparison, more recently arrived mothers and mothers to non-British (though often bilingual and bicultural) children described milder forms of distress. Elodie became a mother soon after moving to the UK following her French partner; she compared her emotional journey postreferendum to the process of grieving: 'I think it's the process of grieving an idea and an ideal. The European ideal? An integration ideal? The grieving process has different stages. There is shock, anger, depression and sadness, acceptation and bouncing back. I went through all these phases.' For Elodie, though Brexit undermines the European ideal she supports, she did not experience it as an attack on and denial of what she and her family had become, as did Sandrine and Mireille. For Elodie, her family situation also meant that life outside the UK 
was a tangible possibility and perhaps a long-term goal. Some other women like Elodie appeared to resolve their 'grieving process' more quickly than their counterparts who had established deep personal and family roots in the UK with their British partners.

Feelings of rejection proved particularly intense for women who felt a strong sense of connection and belonging to the UK. Before the referendum, none of these women had experienced what they recognised as racism. Markers of identity, such as their accent and their sartorial style, had often been commented on; however, these women (who all looked Caucasian) did not interpret these remarks negatively, but welcomed them and found them funny. These comments were interpreted as 'friendly banter' and were used by their recipients as a means of connecting with others. This was made possible by the imagined distinctive position that French movers thought they occupied in the UK, and the imagined privileged relations this position entailed. Brexit was these women's first 'racist' experience (in the UK). Sandrine explained how the Brexit vote transformed the way in which she saw herself in the UK:

This may sound horrible, but I found that before (the referendum) we used to be part of the foreigners who were accepted and liked, and now we are becoming strangers who are no longer liked. I was going through what Polish people must have endured for years. I understood what it was like, and that it must be truly difficult.

Many of the women referred to the existence of foreigners who blend or 'integrate' in their country of residence to different degrees. The French women interviewed often cited Polish migrants as their imagined 'archetypal migrant' at the opposite end of the spectrum of 
social acceptance in the UK. Both groups are European movers; however, French women felt that they differed in terms of their desirability as migrants and foreigners.

This distinction is reflected in the reluctance of many French movers to identify themselves as 'migrants'. Many used 'French in Manchester or in the UK' and some preferred the term 'expat'. Caroline sets herself apart from unwanted migrants: 'I understood the English who wanted to put a stop to migration, to stop the Romanians, the Poles, the Hungarians. (They) no longer want to have foreigners coming to England. But which foreigners? That's the problem; (not) differentiating is the problem.' The referendum, in which none of the respondents could vote, left these women feeling powerless; but up until that point, migrating had been an empowering, 'can-do' experience for them. The Brexit referendum concerned them but their voices were reduced to silence: 'It feels like others decided for me' (Catherine).

The increase in hate crimes post-referendum led many respondents to fear racist abuse for their children and themselves. '(After the referendum,) people who were racists or who wanted to express these sorts of things allowed themselves to do it much more than usual. It made me feel very uncomfortable and I told myself "If it goes on, I will leave." I will never impose that on my children. I cannot tolerate it and I refuse to let my children grow up in this hostility' (Sandrine). In the aftermath of the referendum, the women in the playgroups discussed at length what to tell their children, whom they regarded as the main 'victims' of Brexit. The respondents often described their children as the archetypal Europeans (i.e. born 'hybrid' and living across borders and languages). They feared that Brexit would deprive them of rights (e.g. mobility and residency) and racialise them whilst eroding their sense of Europeanness and stigmatising their mixed transnational identities. Mothers with teenagers worried that Brexit would limit their children's options in terms of studies abroad: 'The future of my children has radically changed' (Sandrine). Unwilling to accept this fate, 
Mireille contemplated sending her children to non-UK universities, which was not something she had considered previously.

\section{Mothering in the UK's changing context of migrant motherhood}

The outcome of the Brexit referendum revealed aspects of British society to which my participants had been oblivious. Insecurity regarding the erosion and loss of an imagined privileged position as 'desirable' foreigners in the UK led them to discover unsuspected commonalities of circumstance they share with other migrant groups. Feelings of loss and rejection were compounded by the fact that these mothers felt Brexit had serious implications for their children's lives and futures. Brexit introduced a new context for migrants and migrant mothers. In this section, I explore how Brexit has affected these women's mothering experiences and practices. It is important to acknowledge that, as Elodie's metaphor of the grieving process suggests, emotions and affect are time-sensitive following the Brexit referendum. Whilst most respondents experienced intense feelings immediately after the referendum, these emotions have somewhat settled down with the passing of time. Nonetheless, some of the doubts and anxieties lingered, disrupting the respondents' sense of ontological security.

After the referendum, many of my participants adapted their mothering practices to the new, seemingly more hostile context. Feeling 'paranoid' post-referendum, some such as Elodie adopted a defensive attitude and avoided engaging with strangers. This had repercussions on her day-to-day management of 'living with difference' for her and her daughter: 'I no longer make an effort to talk. In the park with my daughter, for example... I used to try and speak (in English) with mums and dads. Now, I speak French-full stop.' For others, adaptation meant 'blending in', which in practice resulted in them avoiding speaking 
French in public places. This had a direct impact on their practice of bilingual parenting. For example, Caroline said:

(I felt very uncomfortable) to the point that I had to speak English with my daughters... to show that I am not French. Now I feel a bit better. Before (the referendum), I was proud to speak French with my daughters because it is part of what Europe is about. Now I know things are a bit different, but it (this feeling) is not as strong as it was.

Similarly, Catherine felt deeply hurt by the Leave campaign suggesting that foreigners burdened the National Health Service (NHS) and recalled her behavioural changes after the referendum. She started to feel self-conscious speaking French to her child in her local medical practice, and preferred waiting in silence for her appointment so as not to be identified as a foreign mother. By remaining silent (and not interacting with her child), she may be considered to be a 'bad' mother, but at least other patients would not know she was a foreigner.

Many respondents felt wary of their French accent, whereas they had previously considered it 'funny' or used it as a means to engage in small talk. Edith felt that Brexit complicated her relationships with others. Not knowing how someone voted (which she equated to their feeling towards migrants and her) created social anxieties, which she found difficult to overcome when interacting with others. Many of the women had a preconceived image of Brexiteers, which they used to navigate their post-referendum life in the UK. As the binary categorisation of Leaver versus Remainer cuts across my respondents' class perceptions, they often associated Brexit with working-class rather than middle-class voters. ${ }^{9}$ 
Being in a relationship with a British partner or a fellow foreign national also informed the ways in which the French mothers strategised their day-to-day practices and future plans. My participants in a relationship with a fellow foreigner appeared more belligerent and envisaged moving towards a position of indifference towards British people, albeit reluctantly. Many declared that they would relocate if the situation worsened, which for some had been part of a pre-existing long-term plan. Although they did not want to leave the UK at the time of interview, Brexit led some respondents to consider a future life outside the UK for their families. For all but one respondent with a British partner, Brexit revealed the extent to which their lives were anchored locally; finding employment outside the UK would be difficult for their partner and children who were 'settled' in Manchester. These respondents adopted a more emollient attitude and sought to maintain relations with the 'locals' or 'establish links with Brexiteers' (Sandrine). Many of these respondents knew of family members who had voted for Brexit, which led to feelings of resentment, tension, and sometimes conflicts. Whilst they felt hurt and disappointed, these respondents chose 'to move forward and not be rancorous' (Caroline). Leniency and tolerance (at least with family members) were deemed beneficial in the long run for them and their families.

Whilst all but one respondent involved in a relationship with a British national saw their future in the UK, none of them had yet secured permanent residency status despite meeting the requirements. Some, like Sandrine, thought it was 'hypocritical' to apply for permanent residency since they already lived in the UK for years. Others, like Edith, wanted to wait and see. The impact of Brexit on their rights and quality of life (including that of their child[ren]) would determine whether they would eventually apply for permanent residency, right-to-remain, or British citizenship. None of the women felt psychologically ready to apply for British citizenship and would only consider it as a last resort ('if it has a big impact on my daughters,' said Caroline). Mireille complained that she refused to pay 'more than a thousand 
pounds' to get a British passport. Although cost was frequently mentioned, the main inhibition was associated with their sense of identity: 'I did not come to England to be British. I'm European. I'm one hundred per cent European' (Caroline); 'at the moment I feel bitter about what is happening so I'm not sure I want to swear allegiance to the Queen' (Sandrine).

Many of the married participants felt that being married to a British national would shelter them from any unwanted changes after Brexit (particularly in terms of their right to remain). For example, Caroline was considering dropping her foreign-sounding maiden name from her hyphenated married surname for fear it might harm her career prospects. Several unmarried participants (whether in a relationship with a British or non-British national) were considering getting married in the hope of being recognised as a family unit by the Home Office and securing their future in the UK together. This particularly applied to unemployed and self-employed mothers who expressed concerns about their professional future and their right to remain.

By disrupting these women's sense of ontological security, Brexit forced them to reflect on their future and make subtle adaptations in response to the changing environment. Invisibility, silence and forms of withdrawal have characterised these mothers' day-to-day lives in post-Brexit UK. Feeling rejected, many of these women started revisiting their French cultural roots. 'I really had a huge sense of sorrow and bitterness. I felt rejected. I withdrew into myself. I started reading in French again. I listen to French radio. I watch French TV' (Mireille).

Brexit also led these women to invest more in French-speaking playgroups and networks. Participation in French-speaking groups extended beyond supporting bilingualism and sociability; it also played a critical part in the process of grieving and restoring a sense of normalcy. The women confessed that they felt uncomfortable discussing Brexit outside their 
immediate private circles, yet many needed to voice their opinions and concerns over a matter that had become central in their lives. Feeling silenced or choosing to remain silent, French-speaking playgroups became a welcome space for the mothers to talk. The participants' imagined shared outlook meant these groups were perceived to be a safe space for them to express disappointment, sadness and anger. The women discussed their plans for the future and exchanged knowledge of practical issues such as applying for permanent residency or citizenship. Talking about Brexit with fellow French mothers was cathartic. Being together, 'sharing the same thing', and feeling a sense of solidarity and empathy contributed to the slow restoration of a sense of (post-Brexit) normalcy, in which ethnic bonding assumed new meanings. Interestingly, none of my participants had joined formal lobbying networks of European nationals formed in the aftermath of Brexit. They focused on absorbing the shock, surrounding themselves with co-ethnic support, and continuing their lives in the UK.

\section{Conclusion}

In this study, I have explored the impact of Brexit on the lives of French migrant mothers in Manchester. Pre-referendum, the respondents described socially rewarding experiences of migrant mothering, often acknowledging the privileged position of their lives as middle-class French nationals in the UK. The shock of Brexit forced these women to reflect on their position in the UK. Their narratives suggest a sense of injustice and loss (of 'privileges') and the sudden realisation of their own 'migrant' status. The mothers made subtle adaptations to their mothering practices. Post-referendum, participation in French-speaking children's playgroups assumed new meanings, extending beyond the support of bilingualism and sociability to become a critical part of the process of grieving and restoring a sense of normalcy. Brexit disrupted these women's sense of ontological security and prompted them 
to reconsider their future, either to stay put in the UK or to leave. The complexity and length of the Brexit process have transformed the initial shock into a form of fatigue and normalisation and 'acceptance' (by migrants themselves) of Britain's hostile migratory environment.

Comparing the French migrant mothers' mothering experiences before and after the Brexit referendum, wider contributions to ongoing debates in ethnic and migration studies can be identified. First, the evidence indicates an inadequacy in the terminology currently used to describe migration dynamics. Definitions are imbued with the power to differentiate, and thus the act of defining constitutes a key step in how (family) rights are distributed. Migrants and movers are not equivalent terms that can be used interchangeably. Replacing the term 'migrant' by the term 'mover' (see Cohen and Sirkeci 2013) obscures the existence of persistent hierarchies based on ethnic and national identities that social scientists ought to make visible and challenge. Movers seldom use the term 'migrant' to refer to themselves; as described herein, French mothers describe themselves as 'nationals x in country y' or 'expats'. With this terminology, they actively delineate the contours of their cultural and ethnic identities and assert their imagined position in the migratory landscape. In contrast, the term 'migrant' feels imposed and 'violent', which dehumanises and masks individuality. The 'suspense citizenship' created by the Brexit process forces my respondents to travel along these hierarchies, experiencing a sense of lost privilege and injustice.

Respondents demonstrate a clear understanding of the racial hierarchies that are in operation in the UK (see Ford, 2011). References to how migratory statuses can be racialised and how racialisation can marginalise migrants in the UK are woven into these women's narratives. Predicted changes to their migratory status introduces a sense of differentiated whiteness and loss of invisibility, adding to the erosion of pre-Brexit privileges that were derived from their EU citizenship. Whilst it may be too early to discuss further the 
implications of this 're-classification' in terms of respondents' identification as 'white', these changes result in new found identifications and emergent solidarities, for example with Eastern European migrants (constructed as partially-white - see Fox, Moroşanu and Szilassy, 2012) and outsiders of Europeanness (constructed as non-white - see Goldberg, 2006).

With these hierarchies comes the importance of affect. The loss of privilege described by the French mothers post-referendum has been perceived to be an unjustly imposed downgrade to the category of migrant, a category with which they had not previously associated. This paper argues that migrants and movers ('national $\mathrm{x}$ in country $\mathrm{y}$ ' and expats) co-exist, inhabit and reproduce complex hierarchies based (primarily) on ethnicity and national identity. Movers and migrants are not objective categories whereby migrants and movers are solely defined by their legal status and policies regulating their migration. The categories 'migrants' and 'movers' are affective citizenship statuses that mobile individuals sometimes embrace, sometimes suffer, and through which the desirability of their otherness (and that of others) is felt.

Beyond the importance of affect in the construction of migrants' (sense of) citizenship and justice, evidence suggests the significance of gender dynamics and intersectionality in these processes. Being a mother informs migrant women's everyday lives, their sense of identity and their overall migratory experience. Out of the many roles that migrant women assume, being a mother plays a key role in shaping the women's experience of citizenship in their host country. Kept at the margins of full citizenship, migrant mothers may suffer from 'conflicting' loyalties, which cast doubt on their ability to 'produce' the next generation of citizens (Erel 2009). Reframing migrant mothers as citizens is therefore key to empowering migrant women to transcend restrictive definitions of citizenship (Erel 2009).

Whilst reframing migrant mothers as citizens is paramount to their empowerment, this study suggests that people's affective experiences cannot be overlooked for this process to be 
meaningful. Building on Erel and Ryan's analytical framework (2018) which captures the connections between macro socio-political factors, meso-level networks and individual biographies, this article demonstrates the importance of affect and the normative context of motherhood in either empowering or alienating migrant women. Migrant mothers' (sense of) citizenship and their perception of the normative context inform their mothering practices and intergenerational relations. A supportive context for migrant motherhood combined with a sense of belonging empowers and enables mothers to strategise their own and family agendas. By contrast, when the women perceived their environment to be inimical (to migrants and migrant mothers), they tended to devise strategies to respond to their perceived threats and anticipated risks.

Beyond the importance of affect in gendered migratory experiences, migrant mothers' fragility and susceptibility to political and policy changes is clearly illustrated by my findings. In the four years since the Brexit referendum, there has been no practical change in the status of EU nationals in the UK, yet 'suspense citizenship' and the uncertainty it entails have dramatically changed my respondents' perspectives on their life in the UK. The reification of symbolic borders introduced by the Brexit referendum provoked a symbolic shift whereby movers have become migrants. A perceived hierarchy, once based on individuals' country of origin and ethnicity, is changing into a binary the UK versus the rest paradigm. Conversely, Brexit not only transformed the 'racial' hierarchy into a binary construct, it also relationally reduced EU migrants' understanding of the 'British' to a dichotomy: the 'Remainers' and the others, which highlights how processes of affective citizenships are relational and two-way. These affective processes shape the lives of transnationally mobile individuals, thus affecting their intimate relationships such as the mother-child bond. 
The exploration of motherhood and mothering practices in the context of migration reveals elusive dynamics and hierarchies, which shape mobile individuals' sense of identity and inform the sense of legitimacy attached to their practices. Central to the construction of citizenship and belonging of mobile individuals, perceptions and feelings are highly susceptible to policy changes, which play an important role in their configuration. Understanding the role of the affect and gender in the construction of migrant identities and citizenship statuses is an important task for ethnic and migration scholars in their critique of migratory policies and their human consequences.

\section{Notes}

1. 'In 2017 in England and Wales, $28.4 \%$ of live-born babies had mothers who were born outside the UK; this is the highest percentage on record since 1969 when country of birth was first collected at birth registration' (Office of National Statistics 2018, 2).

2. Fries-Tersch et al. (2018) estimate there were 11.8 million EU 'movers' in 2016, representing $2.3 \%$ of the total EU population.

3. EU14 countries include Austria, Belgium, Denmark, Finland, France, Germany, Greece, Republic of Ireland, Italy, Luxembourg, the Netherlands, Portugal, Spain, and Sweden.

4. The A8/EU-8 countries (Czech Republic, Estonia, Hungary, Latvia, Lithuania, Poland, Slovakia, Slovenia) joined the EU in 2004.

5. The A2/EU-2 countries (Bulgaria and Romania) joined the EU in 2007.

6. This paper only includes data concerning French nationals living in the UK.

7. Participants' quotes are translated from French.

8. Respondents referred to themselves as 'French (in Manchester)', 'expats' and only occasionally 'migrant'. 
9. Interestingly, most of the Brexiteer respondents encountered were family members of their British partner who may or not identify as working class, but were typically older voters.

\section{References}

Arendell, Terry. 2000. “Conceiving and Investigating Motherhood: The Decade's Scholarship.” Journal of Marriage and Family 62 (4): 1192-1207.

Ahmed, Sara. 2007. “A Phenomenology of Whiteness.” Feminist Theory 8 (2): 149-168.

Beaman, Jean. 2019. "Are French People White? Towards an Understanding of Whiteness in Republican France.” Identities 26(5): 546-562.

Benson, Michaela. 2019. "Brexit and the Classed Politics of Bordering: The British in France and European Belongings.” Sociology 54 (3): 501-517.

Brahic, Bénédicte. 2013. “The Politics of Bi-Nationality in Couple Relationships: A Case Study of European Bi-National Couples in Manchester." Journal of Comparative Family Studies 44 (6): 699-714.

Brahic, Bénédicte, and Rowenna Baldwin. 2015. "Reluctant Communities? Exploring The Social Implications of Raising A Bilingual Family for European Movers.” Paper presented at the 12th European Sociological Association Conference, Prague, August $25-28$.

Castles, Stephen. 2010. “Understanding Global Migration: A Social Transformation Perspective." Journal of Ethnic and Migration Studies 36 (10): 1565-1586.

Christou, Anastasia, Adalgisa Giorgio, and Gill Rye. 2015. "Mothering and Migration: Interdisciplinary Dialogues, European Perspectives and International Contexts: Introduction.” Women's Studies International Forum 52: 49-52. 
Cohen, Jeffrey H., and Ibrahim Sirkeci. 2011. Cultures of Migration: The Global Nature of Contemporary Movement. Austin: University of Texas Press.

Cohen, Robin. 2007. "Creolization and Cultural Globalization: The Soft Sounds of Fugitive Power." Globalizations 4 (3): 369-373.

Dodd, Nigel, Michèle Lamont, and Mike Savage. 2017. "Introduction to BJS Special Issue." The British Journal of Sociology 68 (S1): S3-S10.

Donato, Katherine, Donna Gabaccia, Jennifer Holdaway, Martin Manalansan, and Patricia Pessar. 2006. “A Glass Half Full? Gender in Migration Studies.” International Migration Review 40 (1): 3-26.

Electoral Commission. 2016. “EU Referendum Results.” Accessed June 1, 2019. https://www.electoralcommission.org.uk/find-information-by-subject/elections-andreferendums/past-elections-and-referendums/eu-referendum/electorate-and-countinformation.

Erel, Umut. 2009. Migrant Women Transforming Citizenship. Farnham: Ashgate.

Erel, Umut, Tracey Reynolds, and Erene Kaptani. 2018. "Migrant Mothers' Creative Interventions into Racialized Citizenship.” Ethnic and Racial Studies 41 (1): 55-72. Erel, Umut, and Louise Ryan. 2018. "Migrant Capitals: Proposing a Multi-Level SpatioTemporal Analytical Framework.” Sociology 53 (2): 246-263.

Favell Adrian, and Tina Nebe. 2009. "Internal and External Movers: East-West Migration and The Impact of EU Enlargement." In Pioneers of European Integration, Citizenship and Mobility in The EU, edited by Ettore Recchi, and Adrian Favell, 205223. Cheltenham: Edward Elgar.

Favell, Adrian, and Ettore Recchi. 2011. "Social Mobility and Spatial Mobility.” In Sociology of The European Union, edited by Adrian Favell, and Virginie Guiraudon 50-75. Basingstoke: Palgrave. 
Ford, Robert. 2011. “Acceptable and Unacceptable Immigrants: How Opposition to Immigration in Britain is Affected by Migrants' Region of Origin.” Journal of Ethnic and Migration studies 37(7): 1017-1037.

Fortier, Anne-Marie. 2010. "Proximity by Design? Affective Citizenship and the Management of Unease.” Citizenship Studies 14 (1): 17-30.

Fox, Jon, Laura Moroşanu, and Eszter Szilassy. 2012. "The Racialization of the New European Migration to the UK.” Sociology 46 (4): 680-695.

Fries-Tersch, Elena, Tugce Tugran, Ludovica Rossi, and Harriet Bradley. 2018. "The 2017 Annual Report on Intra-EU Labour Mobility.” Accessed 1 June 2019. http://cite.gov.pt/pt/destaques/complementosDestqs2/Intra_EU_labour_mobility_2017 .pdf

Goldberg, David. 2006. “Racial Europeanization.” Ethnic and Racial Studies 29(2): 331-364. Hill Collins, Patricia. 2016. "Shifting the Center, Race, Class and Feminist Theorising about Motherhood." In Mothering: Ideology, Experience, and Agency, edited by Evelyn Nakano Glenn, Grace Chang, and Linda Rennie Forcey, 45-66. London: Routledge.

Kofman, Eleonore. 2000. "The Invisibility of Skilled Female Migrants in European Migratory Spaces.” International Journal of Population Geography 6 (1): 45-59.

Kofman, Eleonore. 2004a. "Family-Related Migration: A Critical Review of European Studies." Journal of Ethnic and Migration Studies 30 (2): 243-262.

Kofman, Eleonore. 2004b. “Gendered Global Migrations.” International Feminist Journal of Politics 6 (4): 643-665.

Kunz, Sarah. 2019. "Expatriate, Migrant? The Social Life of Migration Categories and the Polyvalent Mobility of Race.” Journal of Ethnic and Migration Studies, 46(11): 21452162.

Lawler, Steph. 2000. Mothering the Self: Mothers, Daughters, Subjects. Routledge: London. 
Lopez Rodriguez, Magdalena. 2010. “Migration and A Quest for 'Normalcy'. Polish

Migrants and the Capitalization of Meritocratic Opportunities in the UK." Social Identities 16 (3): 339-358.

Manchester City Council. 2015. "Manchester Migration: A Profile of Manchester's Migration Patterns.” Accessed June 1, 2019. http://manchester.gov.uk/ ... /id/ ... /a05_profile_of_migration_in_manchester_2015.pdf

McNeil, Robert. 2013. “Migrants in The Newspapers: An Influx of Illegal, Failed, Economic Terrorists?” The Migration Observatory. Accessed 1 June 2019. http://migrationobservatory.ox.ac.uk/press/migrants-in-the-newspapers-an-influx-ofillegal-failed-economic-terrorists/

Miller, Tina. 2005. Making Sense of Motherhood: A Narrative Approach. Cambridge: Cambridge University Press.

Office of National Statistics. 2016. "Living Abroad: Migration Between Britain and France.” Accessed 1 June 2019. https://www.ons.gov.uk/peoplepopulationandcommunity/populationandmigration/inte rnationalmigration/articles/livingabroad/dynamicsofmigrationbetweenbritainandfranc e\#how-many-french-citizens-are-there-in-the-uk

Office of National Statistics. 2018. "Births by Parents' Country of Birth, England and Wales: 2017.” Accessed 1 June 2019. https://www.ons.gov.uk/peoplepopulationandcommunity/birthsdeathsandmarriages/liv ebirthsbulletins/parentscountryofbirthenglandandwales/2017

Phoenix, Ann, Anne Woollett, and Eva Lloyd. 1991. Motherhood: Meaning, Practices and Ideologies. London: Sage.

Reynolds, Tracey, and Umut Erel. 2018. "Migrant Mothers: Kin Work and Cultural Work in Making Future Citizens." Families, Relationships and Societies 7 (3): 357-363. 
Ryan, Louise. 2007. "Migrant Women, Social Networks and Motherhood: The Experiences of Irish Nurses in Britain.” Sociology 41 (2): 295-312.

Ryan, Louise, and Jon Mulholland. 2014. "'Wives Are the Route to Social Life': An Analysis of Family Life and Networking amongst Highly Skilled Migrants in London.” Sociology 48 (2): 251-267.

Ryan, Louise, Rosemary Sales, Mary Tilki, and Bernadetta Siara. 2009. "Family Strategies and Transnational Migration: Recent Polish Migrants in London." Journal of Ethnic and Migration Studies 35 (1): 61-77.

Sirkeci, Ibrahim, and Jeffrey H. Cohen. 2016. "Cultures of Migration and Conflict in Contemporary Human Mobility in Turkey.” European Review 24 (3): 381-396. 